\title{
Long-term crude probabilities of death among breast cancer patients by age and stage: a population-based survival study in Northeastern Spain (Girona-Tarragona 1985-2004)
}

\author{
R. Clèries ${ }^{1,2}$ (I) A. Ameijide ${ }^{3} \cdot$ M. Buxó ${ }^{4} \cdot$ J. M. Martínez ${ }^{5} \cdot$ R. Marcos-Gragera ${ }^{6,7,8} \cdot$ M.-L. Vilardell $^{6,7} \cdot$ M. Carulla $^{3}$. \\ Y. Yasui ${ }^{9} \cdot$ M. Vilardell $^{10} \cdot$ J. A. Espinàs ${ }^{1} \cdot$ J. M. Borràs ${ }^{1,2} \cdot$ J. Galceran $^{3,11} \cdot$ À. Izquierdo $^{6,7,12}$
}

Received: 19 January 2018 / Accepted: 23 February 2018 / Published online: 6 March 2018

(c) The Author(s) 2018. This article is an open access publication

\begin{abstract}
Background We provide population-based long-term survival indicators of breast cancer patients by quantifying the observed survival, and the probabilities of death due to breast cancer and to other causes by age and tumor stage at diagnosis.

Methods We included a total of 10,195 female patients diagnosed before 85 years with invasive primary breast cancer in Girona and Tarragona during the periods 1985-1994 and 1995-2004 and followed-up until December 31st 2014. The survival indicators were estimated at 5,10,15 and 20 years of follow-up comparing diagnostic periods.

Results Comparing diagnostic periods: I) the probability of death due to other causes did not change; II) the 20-year survival for women diagnosed $\leq 49$ years increased 13\% (1995-2004 $=68 \% ; 1985-1994: 55 \%)$, whereas their probability of death due to breast cancer decreased at the same pace $(1995-2004=29 \% ; 1985-1994=42 \%)$; III) at 10 years of follow-up, decreases in the probabilities of death due to breast cancer across age groups switched from 11 to $17 \%$ resulting in a risk of death reduction of $19 \%$ after adjusting by stage. During 1995-2004, the stage-specific 10-year probabilities of death due to breast cancer switched from: 3-6\% in stage I, 18-20\% in stage II, 34-46\% in stage III and surpassed $70 \%$ in stage IV beyond 5 years after diagnosis.

Conclusions In our study, women diagnosed with breast cancer had higher long-term probability to die from breast cancer than from other causes. The improvements in treatment and the lead-time bias in detecting cancer in an early stage resulted in a reduction of $19 \%$ in the risk of death between diagnostic periods.
\end{abstract}

Keywords Breast cancer $\cdot$ Survival $\cdot$ Probability of death $\cdot$ Stage $\cdot$ Age

$\begin{array}{ll}\text { Abbreviations } \\ \text { BC } & \text { Breast cancer } \\ \text { OS } & \text { Observed survival } \\ \text { PBC } & \text { Probability of death due to BC } \\ \text { POC } & \text { Probability of death due to other causes } \\ \text { AJCC } & \text { American Joint Committee on Cancer }\end{array}$

Electronic supplementary material The online version of this article (https://doi.org/10.1007/s12094-018-1852-1) contains supplementary material, which is available to authorized users.

R. Clèries

r.cleries@iconcologia.net

Extended author information available on the last page of the article

\section{Introduction}

Breast cancer (BC) is the most frequent tumor and the first cause of cancer death among European women in the recent years [1]. In Spain, it has been estimated that 28,000 new BC cases were diagnosed in 2015, with an incidence rate (adjusted for the European population) of 88.3 cases per 100,000 women-years, that leads to an intermediate position in Europe [2]. It is estimated that 1 in 9 Spanish women will develop BC throughout their life [3], with a mean age at diagnosis of 60 years, although $\mathrm{BC}$ incidence rates have shown a downturn since 2001 among Spanish women over 45 [4].

Improvements in 5-year $\mathrm{BC}$ survival have been observed [5-8] in parallel with a decline in the risk of BC mortality specially marked in women under 50 years of age [9]. Since life expectancy can lengthen by several decades in young $\mathrm{BC}$ patients [10], to provide long-term survival estimates 
is called for. To our knowledge, population-based survival studies in Spain have been provided up to 5-year survival estimates [5-7, 11], but not beyond this follow-up. It is of crucial interest the assessment of the most recent survival estimates, since several international studies have suggested a non-decreasing excess mortality beyond 10 years after BC diagnosis [12-18].

In a previous study, we provided long-term estimates of the survival probabilities of $\mathrm{BC}$ patients diagnosed before 50 years by stage and period of diagnosis using a small cohort $(N=998)$ from the population-based cancer registry of Girona [7]. In the present study, we provide survival indicators of BC patients based on a larger cohort of $N=10,195$ women from two population-based cancer registries, Girona and Tarragona, taking into account the age and $\mathrm{BC}$ stage and period of diagnosis. Our aim is in quantifying the contribution of $\mathrm{BC}$ to overall mortality, assessing the long-term crude probabilities of death, by age and stage, due to $\mathrm{BC}$ and other causes among patients diagnosed before 84 years.

\section{Materials and methods}

\section{Data}

$\mathrm{BC}$ data was obtained from the population-based cancer registries of Girona and Tarragona, which cover a population of 771,854 women (2011 Catalonia census) [19]. Each woman with $\mathrm{BC}$ in these provinces has been followed-up to December 31st, 2014. In addition to the active and passive follow-up via hospitals, two passive follow-ups were performed using record linkage: one linking $\mathrm{BC}$ data with the Catalonian Mortality Registry (which covers the four Catalan provinces, Girona, Tarragona, Lleida and Barcelona) and another linking data with the National Death Index of the Spanish Ministry of Health. The patients not found to be dead at the end of follow-up were considered as censored.

We included a total of $N=10,195$ female patients aged 15-84 years and diagnosed with invasive primary BC (codes 174 and $\mathrm{C} 50$ of the 9th and 10th editions of the International Classification of Diseases, ICD-9 and ICD-10, respectively) during the time periods $1985-1994(N=4211)$ and 1995-2004 $(N=5984)$. From these, data on the stage at diagnosis was extracted through medical records review. Variables considered for the analysis were age, partitioned into $\leq 49$, (49-59), (59-74) and (74-84), and stage at diagnosis. Stage classification was based on the TNM classification system unified to the 5th edition of the American Joint Committee on cancer staging manual [20] to compare the survival indicators by stage between 1985-1994 and 1995-2004. Patients were classified as stage I, II, III and IV when staging was available at the moment of diagnosis, and missing stage otherwise.

\section{Statistical analyses}

We calculated the observed survival (OS), and the probabilities of death due to BC (PBC) and other causes (POC) by age and stage at diagnosis at 5, 10, 15 and 20 years of follow-up and we compared these three probabilities between time periods at diagnosis 1985-1994 and 1995-2004 and across age groups. Since life expectancy among Catalan women is 90 years [19], we did not estimate these probabilities beyond 5 years of follow-up for patients aged between 74 and 84 years at diagnosis. In the same line, we did not estimate these probabilities beyond 15 years of follow-up for patients aged between 59 and 74 years at diagnosis.

In brief, up to year $T, P(t \leq T)$ is the cumulative probability to die from any cause in the cohort, whereas $\operatorname{OS}(T>t)$ is the cumulative probability to survive in the cohort beyond the year $T$, where $\operatorname{OS}(T>t)+P(t \leq T)=1$. The $P(t \leq T)$ can be estimated as a sum of two probabilities: $P B C(t \leq T)$ is the estimated cumulative probability to die due to the disease under study, BC in our case, and $\operatorname{POC}(t \leq T)$, the estimated cumulative probability to die due to causes other than the cancer of interest [21]. These probabilities can be estimated making use of the excess hazard of death $[22,23]$ under a competing risk's approach to survival, as described in a previous study [7]. This approach allows providing estimates of PBC and POC without knowing the exact cause of death [7, $22,23]$, where it is only needed to know if the patient dies or not because of any cause at the end of study. Therefore, since $\operatorname{OS}(t>T)+\operatorname{PBC}(t \leq T)+\operatorname{POC}(t \leq T)=1$, we will present these probabilities depicted in a survival graph in the results section. We derived their corresponding 2.5, and 97.5\% percentiles using the R-library relsurv [23].

Since the closing date of follow-up was December $31^{\text {st }}$, 2014, for patients diagnosed during 1995-2004, we estimated the probabilities of interest beyond 10 years of follow-up using different cohorts, as performed in the previous study [7]. Therefore, 11-year follow-up was estimated using the patients diagnosed during the period 1995-2003, whereas 12-year follow-up was estimated using the patients diagnosed during the period 1995-2002 and so on up to 19 years. We used the cohort of patients diagnosed in 1994 to estimate these probabilities at 20-year follow-up.

First we assessed up to 20-year survival estimates between periods of diagnosis across age groups. Second, we compared 10-year OS between 1985-1994 and 1995-2004 across stage and age groups. A Cox proportional hazards model was used to assess hazard ratios of all-cause mortality by age, stage and period of diagnosis. Finally, since stage information was available in $86.2 \%$ of the patients diagnosed during 1995-2004, 10-year estimates of the probabilities of interest provide the most recent long-term survival indicators by age and stage in Girona and Tarragona. 
The Supplementary material file presents additional tables, figures and an extension of the statistical methods.

\section{Results}

\section{Comparison of long-term survival between 1985- 1994 and 1995-2004 by age groups}

Comparing the time periods 1985-1994 and 1995-2004, there were no significant differences in the age distribution of the patients considered in the cancer registries, see Table 1. Table S1 in the supplementary material presents survival indicators and crude probabilities of death by period of diagnosis across specific age groups. Figure 1 depicts the $\mathrm{PBC}, \mathrm{POC}$ and the OS comparing survival indicators by period of diagnosis in women $\leq 49$ and $>49$. This figure shows the improvement in OS in parallel with the reduction in the PBC, whereas POC did not change between diagnostic periods. Worth noting is that, among women $\leq 49,20$-year OS for women was 55\% $(\mathrm{PBC}=42 \%)$ if they were diagnosed during 1985-1994, whereas based on our estimations, it could reach $68 \%(\mathrm{PBC}=29 \%)$ if they were diagnosed during 1995-2004.

Comparing 10-year probabilities of death due to BC and OC by period of diagnosis and age group (Fig. 2), differences in the PBC between 1985-1994 and 1995-2004 were 11\% among women $\leq 49$ (1985-1994: 33\%;1995-2004: 22\%), 17\% among women (50-59) (1985-1994: 37\%; 1995-2004: $20 \%$ ), and 14\% among women (60-74) (1985-1994: 37\%; 1995-2004:23\%), and 10\% among women aged (74-84). PBC surpassed POC in all age groups except in the oldest age group, where confidence intervals of POC overlap those of $\mathrm{PBC}$ beyond 5 years of follow-up. Beyond 10 years of follow-up (Table S1), the largest differences in PBC between periods could have reached $12 \%$ among women aged (59-74) at 15 years (PBC 41\% in 1985-1994; $29 \%$ in 1995-2004) and 20\% among women aged (49-59) at 20 years (48\% in 1985-1994; 28\% in 1995-2004). Differences in the OS between diagnostic periods are similar to those found in the PBC.

Table 1 Age-group distribution of the breast cancer patients included in the study during the time periods 1985-1994 and 1995-2004

\begin{tabular}{lrllll}
\hline Age & $1985-1994$ & & & $1995-2004$ & \\
\cline { 2 - 3 } \cline { 6 - 6 } & $N$ & $(\%)$ & & $N$ & $(\%)$ \\
\hline $0-49$ & 1110 & 26.4 & & 1561 & 26.1 \\
$50-59$ & 844 & 20.0 & & 1307 & 21.8 \\
$60-74$ & 1564 & 37.1 & & 2074 & 34.7 \\
$75-84$ & 693 & 16.5 & & 1042 & 17.4 \\
TOTAL & 4211 & 100 & & 5984 & 100 \\
\hline
\end{tabular}

\section{Comparison of observed survival by age-stage between diagnostic periods}

Table 2 presents the stage distribution across age groups by period of diagnosis. Stage was available in $20.6 \%$ $(N=867)$ of the patients diagnosed during the period 1985-1994 and in $86.2 \%(N=5160)$ in those patients diagnosed during 1995-2004. Among patients with staging information in 1985-1994, there was a higher percentage of patients diagnosed in Stage I during 1995-2004 (34.6\%) than during 1985-1994 (26.5\%) and a higher percentage of patients diagnosed in stage IV (13.3 vs $6.8 \%$ ) than during 1995-2004 (6.8\%). Differences in the mean age at diagnosis were also assessed and not found to be statistically significant. We also compared 10-year OS between time periods across stages: I) hazard rates in periods 1985-1994 and 1995-2004 were of similar magnitude by age and stage (Table 3 ), but showing that patients diagnosed during 1995-2004 had 19\% reduction in risk of death compared to those diagnosed in 1985-2004; II) we found significant differences in survival between periods in stage I patients (Supplementary material: Figure S1 Wilcoxon test $p<0.001$; Table S2 10-year OS in 1985-1994: $85 \% ; 1995-2004: 89 \%$ ) and in stage IV (Wilcoxon test $p<0.05$; 10-year OS in 1985-1994: 2\%; 1995-2004: 7\%).

\section{Age-stage observed survival and crude probabilities of death for patients diagnosed during 1995-2004}

Table 4 presents the 5-year and 10-year OS and the crude probabilities of death for the cohort of patients diagnosed during 1995-2004 by age and stage at diagnosis. Differences in 5-year OS switched from 7 to $11 \%$ comparing stages I and II, and from 13 to $22 \%$ comparing stages II and III. We note that the PBC switched from 1 to $3 \%$ in stage I, from 9 to $12 \%$ in stage II and from 23 to $34 \%$ in stage III. The PBC in stage IV patients was estimated to surpass $70 \%$ in all age groups, since these patients showed that less than $29 \%$ and less than $20 \%$ could survive more than 5 years among those diagnosed $\leq 49$ years and beyond 49 years, respectively. These figures must be interpreted with caution due to the small sample size (less than 30 patients at risk).

Similar gradient of differences was found in 10-year OS: $13-18 \%$ comparing stages I and II, and 14-23\% comparing stages II and III. The 10-year PBC in 1995-2004 switched from 3\% (ages (49-59]) to 6\% ( $\leq 49)$ in stage I, $18 \%(49-59)$ to $20 \%$ in stage II and from $34 \%(\leq 49)$ to $46 \%(59-74)$ in stage III. In stage IV patients, PBC surpassed $88 \%$ in all age groups and a very small sample size (less than 10 patients) could reach 10-year follow-up. 


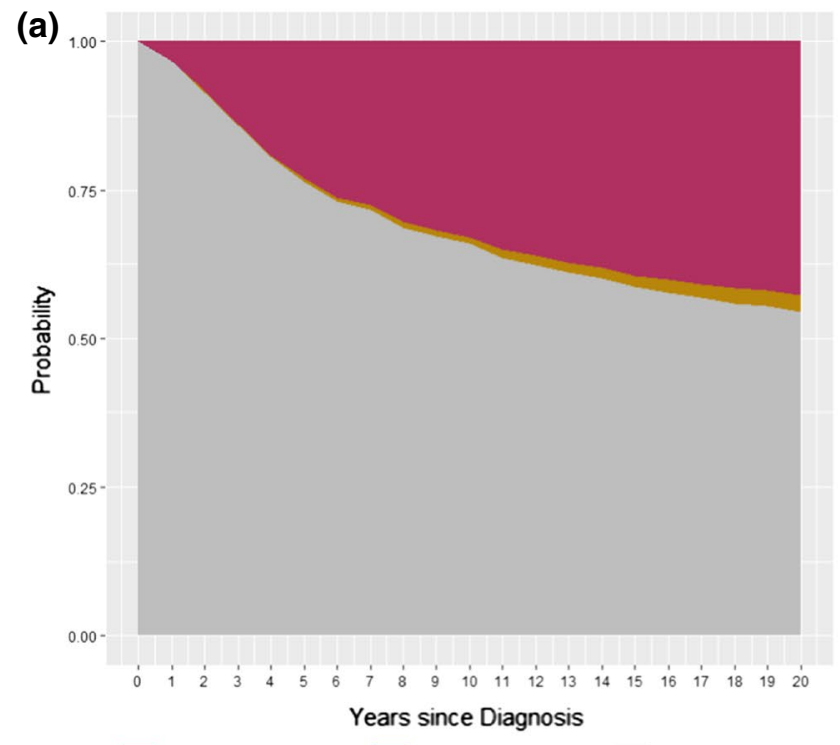

Die from Breast Cancer Die from other causes Observed Survival

(c)

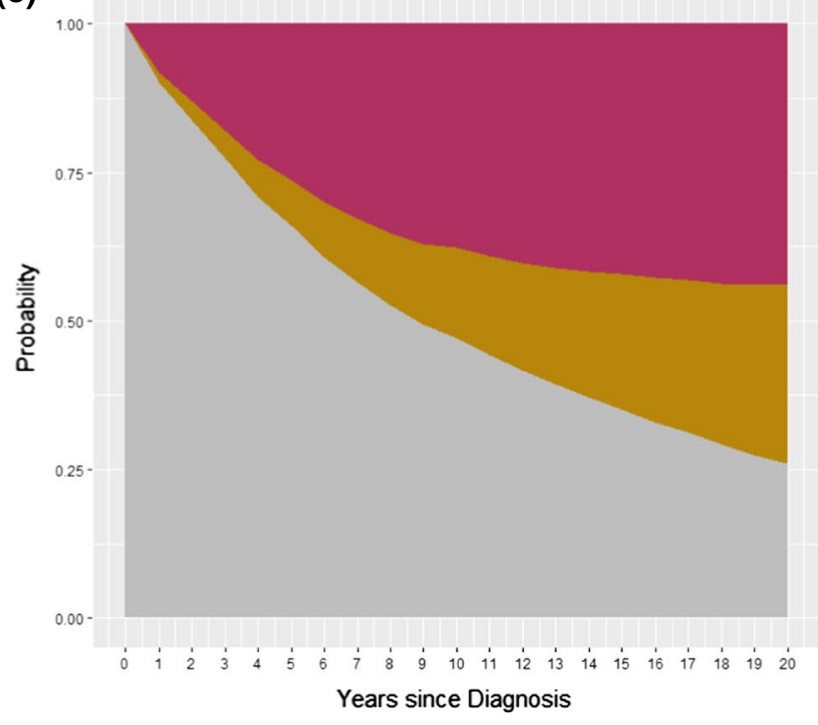

Die from Breast Cancer Die from other causes Observed Survival

Fig. 1 Long-term survival of breast cancer patients diagnosed in Girona and Tarragona before 85 years of age: a diagnosed $\leq 49$ years during 1985-1994; b diagnosed $\leq 49$ years during 1995-2004; c diagnosed > 49 years during 1985-1994; d diagnosed > 49 years during 1995-2004. *Since complete follow-up until December 31st,

\section{Discussion}

We have estimated that risk of death among BC patients was reduced by 19\% in 1995-2004 compared to 1985-1994 and the improvement in 10-year survival between the two periods of diagnosis was mainly due to the decrease in the PBC, since the POC did not change between these time periods. We have estimated that the

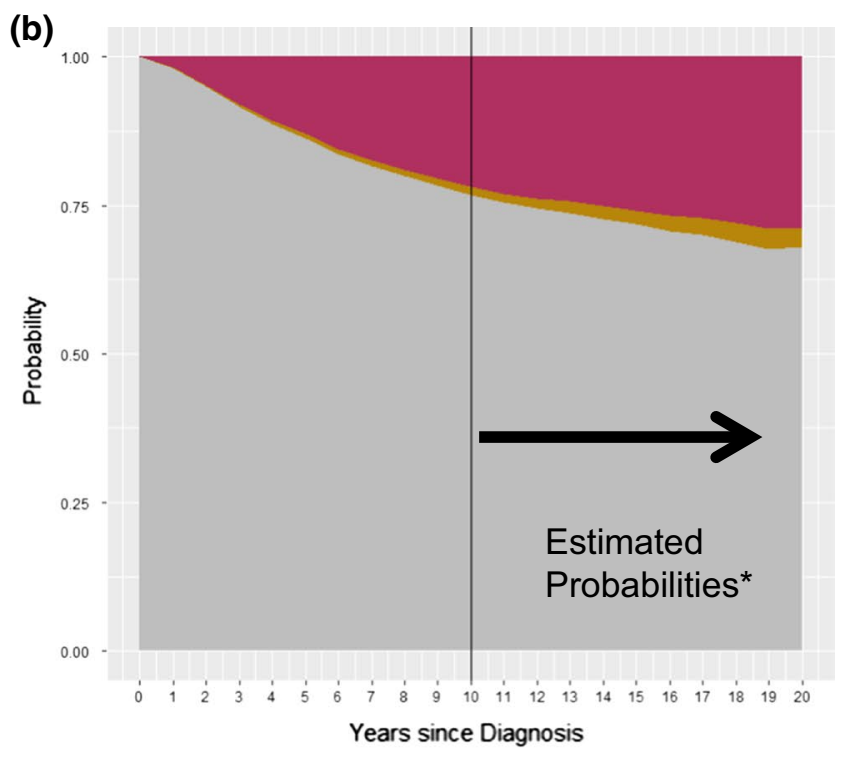

Die from Breast Cancer Die from other causes Observed Survival

(d)

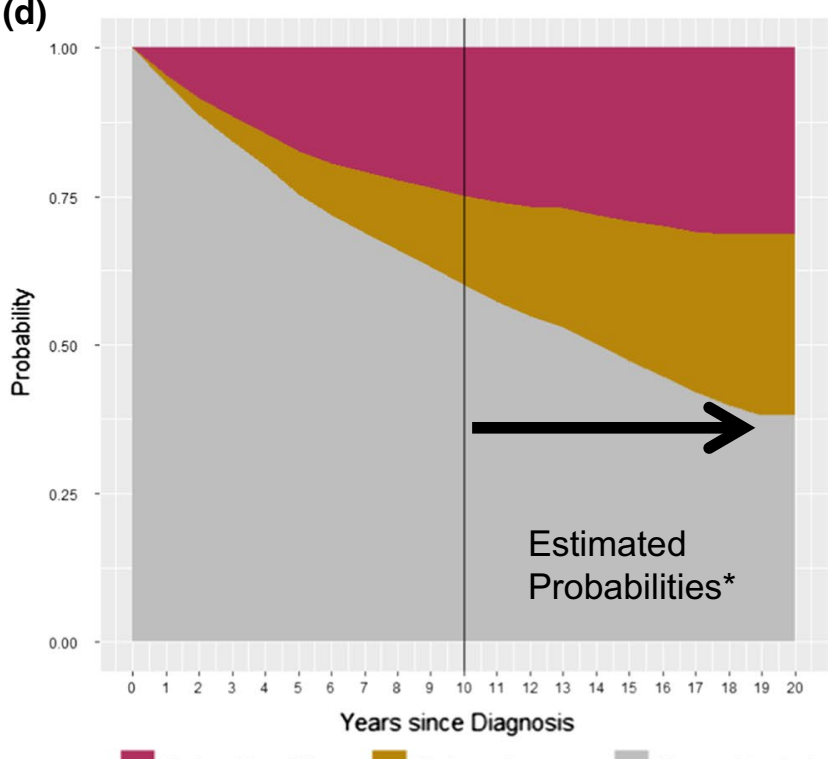

2014 for patients diagnosed between 1995-2004 was 10 years, follow-up beyond 10 years was estimated using the cohorts diagnosed between 1995-1993 (11-year probabilities), 1995-1992 (12-year probabilities) and so on

difference in the PBC between diagnostic periods may continue or even increase beyond 10 years of follow-up among women diagnosed before 60 years. These survival improvements between periods of diagnoses could be due to better survival prospects for stage I and stage IV patients in 1995-2004 compared to 1985-1994. The most recent estimates of 10-year PBC among BC patients could switch from 3 to $6 \%$ in stage I, 18 to $20 \%$ in stage II and 34 

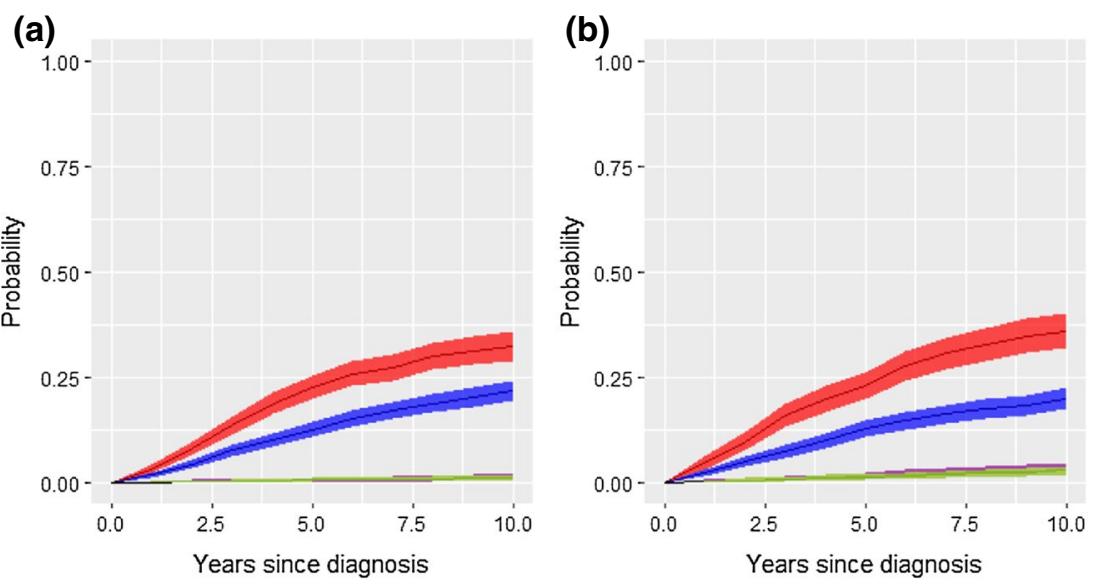

(d)

(c)

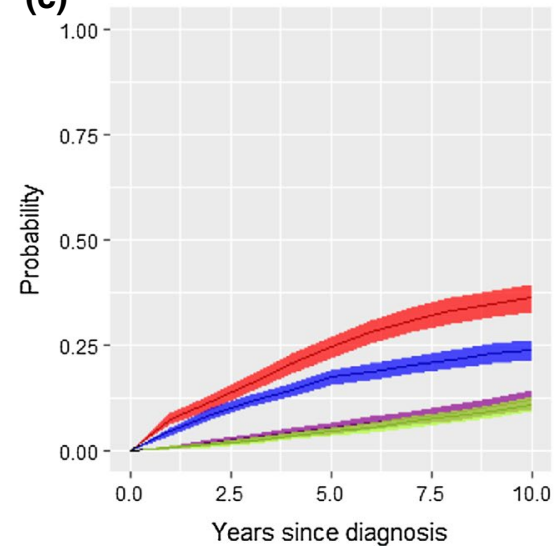

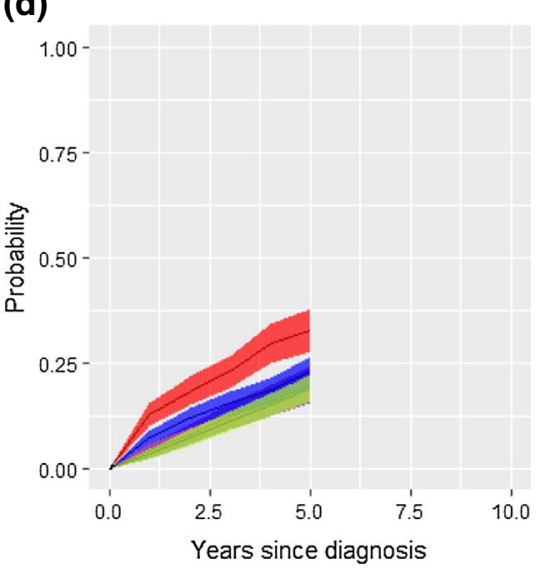

Breast Cancer (PBC): 1985-1994

Other Causes (POC) : 1985-1994

Breast Cancer (PBC) : 1995-2004

Other Causes (POC) : 1995-2004

POC: Probability to die from Other Causes

Fig. 2 Comparison of the 10-year probabilities of death due to breast cancer and other causes between diagnostic periods 1985-1994 and 19952004 by age groups: $\mathbf{a} \leq 49$ years; $\mathbf{b}(50-59)$ years; $\mathbf{c}(60-74)$ years; $\mathbf{d}(75-84)$ years. Shaded bands represent $95 \%$ confidence intervals

Table 2 Stage-distribution and mean age at diagnosis within stage between periods 1985-1994 and 1995-1994

\begin{tabular}{llllll}
\hline Stage & $1985-1994(N)(\%)(\% *)$ & Mean age & $1995-2004(N)(\%)(\% * *)$ & $\begin{array}{c}\text { Mean age } \\
\text { Differences stage (differ- } \\
\text { ence) }(95 \% \mathrm{CI})\end{array}$ \\
\hline I & $230(5.5)(26.5)$ & 56.5 & $1783(29.8)(34.6)$ & 58.6 & $-8.1 * * *(-11.2 ;-4.1)$ \\
II & $392(9.3)(45.2)$ & 55.6 & $2300(38.4)(44.6)$ & 58.9 & $0.6(-3.1 ; 4.1)$ \\
III & $130(3.1)(15.0)$ & 56.8 & $724(12.1)(14.0)$ & 59.6 & $1.0(-1.6 ; 3.5)$ \\
IV & $115(2.7)(13.3)$ & 61.6 & $353(5.9)(6.8)$ & 63.4 & $6.46^{* * *}(3.9 ; 8.9)$ \\
Total with stage $(N)$ & $867(20.6)(100)$ & 56.8 & $5160(86.2)(100)$ & 59.2 & - \\
Unknown stage & $3344(79.4)(-)$ & 60.5 & $824(13.8)(-)$ & 63.9 & - \\
Total & $4211(100)(-)$ & 59.8 & $5984(100)(-)$ & 59.9 & - \\
\hline
\end{tabular}

$\%$, Percentage with respect to the total in each time period

\%*, Percentage with respect to $N=867$ cases with stage confirmed during 1985-1994

$\% * *$, Percentage with respect to $N=5160$ cases with stage confirmed during 1995-2004

Mean age mean age at diagnosis

Differences stage differences in the percentage of patients in Stage

95\% CI 95\% confidence interval of the difference

$* * * 95 \%$ confidence interval of the difference does not include 0 
Table 3 All-cause mortality adjusted by age and stage using a Cox model

\begin{tabular}{|c|c|c|c|c|c|c|c|c|c|c|}
\hline & \multicolumn{3}{|c|}{ 1985-1994 } & \multicolumn{3}{|c|}{ 1995-2004 } & & \multicolumn{3}{|c|}{ 1985-2004 } \\
\hline & HR & \multicolumn{2}{|c|}{$95 \%$ CI } & HR & \multicolumn{2}{|c|}{$95 \%$ CI } & & HR & \multicolumn{2}{|c|}{$95 \%$ CI } \\
\hline$\leq 49$ & Ref. & & & Ref. & & & & Ref. & & \\
\hline$(50-59)$ & 1.17 & 1.01 & 1.35 & 1.06 & 0.91 & 1.06 & & 1.12 & 1.01 & 1.24 \\
\hline$(60-74)$ & 1.52 & 1.34 & 1.72 & 1.54 & 1.36 & 1.54 & & 1.54 & 1.41 & 1.68 \\
\hline$(75-84)$ & 3.22 & 2.82 & 3.68 & 3.06 & 2.7 & 3.06 & & 3.17 & 2.9 & 3.48 \\
\hline \multicolumn{11}{|l|}{ Stage } \\
\hline I & Ref. & & & Ref. & & & & Ref. & & \\
\hline II & 1.72 & 1.22 & 2.43 & 2.22 & 1.93 & 2.22 & & 2.09 & 1.84 & 2.37 \\
\hline III & 3.83 & 2.63 & 5.56 & 4.36 & 3.74 & 4.36 & & 4.09 & 3.55 & 4.72 \\
\hline IV & 13.91 & 9.77 & 19.78 & 17.18 & 14.62 & 17.18 & & 15.10 & 13.07 & 17.45 \\
\hline \multirow[t]{2}{*}{ Missing } & 3.22 & 2.39 & 4.35 & 3.65 & 3.14 & 3.65 & & 3.48 & 2.98 & 4.06 \\
\hline & & & & & & & $\begin{array}{l}\text { Period } \\
\text { 85-94 } \\
95-04\end{array}$ & $\begin{array}{l}\text { Ref } \\
0.81\end{array}$ & 0.71 & 0.91 \\
\hline
\end{tabular}

Period period of diagnosis, $H R$ hazard ratio, 95\% CI 95\% confidence interval, Ref reference category to $46 \%$ in stage III, whereas PBC surpasses $70 \%$ in stage IV beyond 5 years of diagnoses.

Our approach has several strengths, in comparison with previous survival studies. First, we provide estimates of the crude probabilities of death due to $\mathrm{BC}$ and other causes using population-based cancer registry data from a Spanish cohort of $\mathrm{BC}$ patients, and, to date, this is the first study of this type carried out in Spain. These probabilities can be used as indicators to assess the improvement in overall OS and in quantifying the contribution of the disease to overall mortality [22]. Our approach makes a major difference with relative survival. Relative survival is used as population-based cancer survival indicator and as estimator for the net survival, but relative survival is not a survival probability measure $[7,21$, 22]. Second, we provided the most recent estimates of the 10 -year figures of these probabilities, where our study had 86.2\% completeness of this information in 1995-2004.

It is worth noting the strength limitation related with staging classification between diagnostic periods in our study, which was based on the 5th edition of the AJCC staging manual [20]. Since stage migration due to different classifications could artifactually inflate cancer survival rates by shifting patients with better prognosis group into a worse prognosis group [24], we used unified staging classification to minimize this bias. However, there was a limitation related with survival outcomes in the classification of patients making use of the AJCC fifth edition, since differences in survival among $\mathrm{BC}$ cases classified into stage IV could exist but not detected using this classification. The sixth edition of the AJCC has further amended the staging classification of patients with supraclavicular metastases at diagnosis to include them into the IIIC category [25], since evidence suggests that these patients had similar outcomes than stage IIIB patients and even better outcomes than patients with visceral stage IV disease [26]. There are other limitations to be noted in the survival comparison between periods of diagnosis. Survival estimates beyond 10 year for patients diagnosed during 1995-2004 were estimated using different subcohorts of patients during this time period. Second, availability of stage information in 1985-1994 was limited to $N=867$ patients and probability estimates drawn from stage indicators in this time period could not be robust. These could also be biased, since patients with stage information in 1985-1994 had better survival than patients without this information, and this may lead to an underestimation of the survival differences between time periods (Supplementary material: Table S3).

In our study, PBC substantially decreased beyond 1994, but significant excess mortality may remain beyond 10 years after diagnosis. This is in agreement with recent long-term survival studies [7, 18, 27]. Improvements in BC survival between 1985-1994 and 1995-2004 in Spain could be attributable to changes due to BC screening, active in Girona and Tarragona since 1998-1999 [3], management and treatment [6]. In this line, we detected a $19 \%$ of risk of death reduction for $\mathrm{BC}$ patients diagnosed beyond 1995. Since BC screening is related to lead-time bias, it may increase the number of $\mathrm{BC}$ diagnosed at early stages (I) and decrease that number at advanced stages (IV). However, it is also difficult to quantify the contribution of $\mathrm{BC}$ screening in the mortality reduction without information about the diagnostic method, clinical or by screening, of tumor [28-30].

The introduction of the screening program may imply a reduction in advanced invasive cancers and then patient's risk of mastectomy or chemotherapy for breast cancer, or side effects of these, may decrease [31]. In 1994, when most of the screening in Catalonia was opportunistic, rates of screening mammography switched from $27 \%$ (women aged 50-64) to $43 \%$ (women aged $40-49$ ), whereas in $2004,61.2 \%$ of the invited women participated in the national $\mathrm{BC}$ screening 


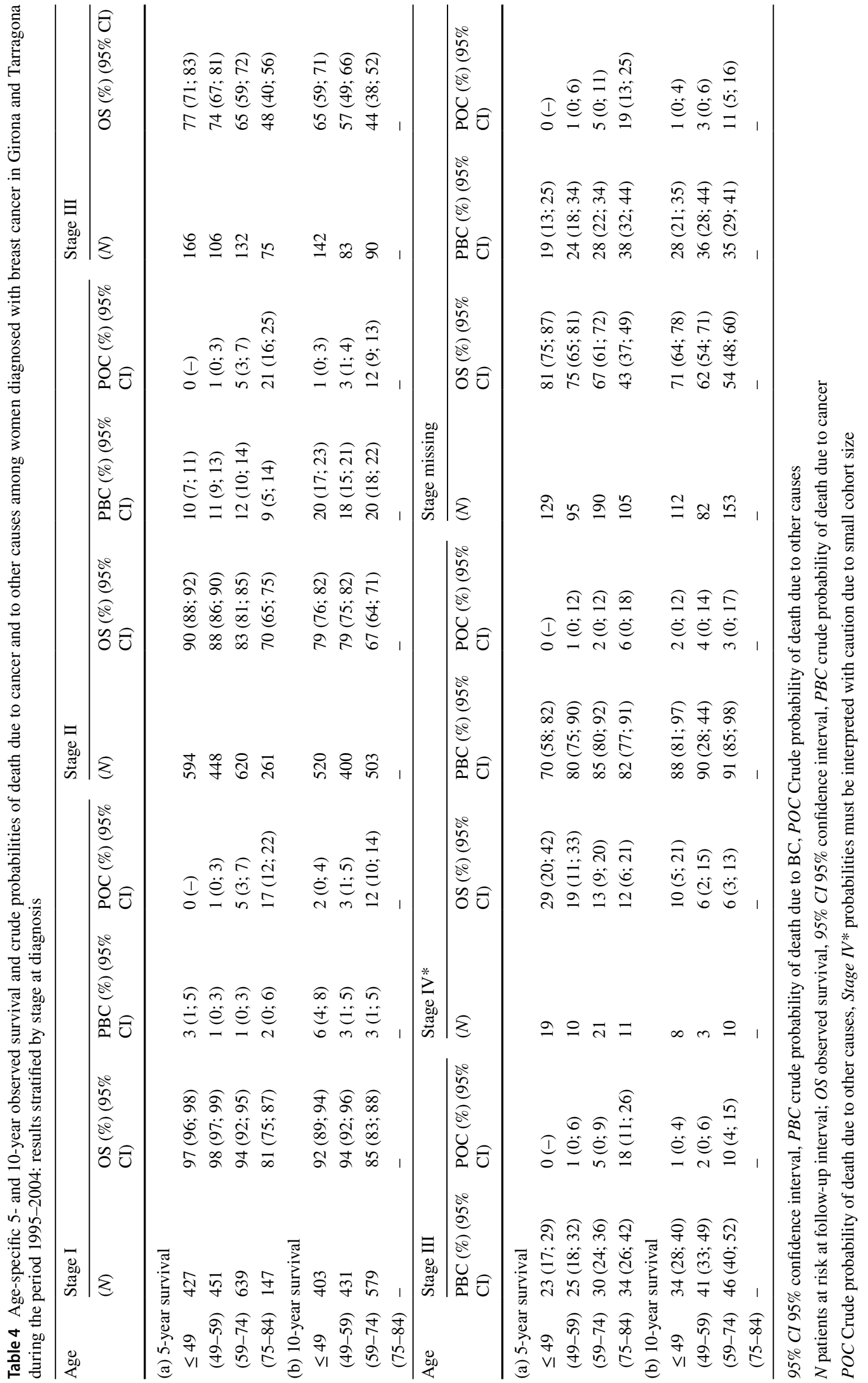


program and $75.7 \%$ either participated in that program or reported that they had received recent mammograms [30]. Overdiagnosis caused by the screening [30] may also be related with the improvement in survival prospects between periods. The influence of a potential stage migration (Will Rogers phenomenon) is a factor that could have influenced changes in survival by stages but not in the global survival [24]. On the other hand, the contribution in the reduction of $\mathrm{BC}$ mortality by treatment improvements is also difficult to quantify, since we found that hazard ratios by age and stage were of similar magnitude between diagnostic periods.

Our probability estimates are based in a competing' risks modeling for which we attribute the excess risk of death of our patients to BC. This can be seen as the death probabilities that the cancer patients could "expect to have" in the hypothetical scenario where cancer patients have the same death risks as the general population [7]. If we compare the 10-year $\mathrm{PBC}$ and POC estimates with the cause-specific proportion of deaths obtained making use of the death certificates (Supplementary material: Table $\mathrm{S} 4$ ) considering all age groups, the difference between PBC and the proportion of deaths due to $\mathrm{BC}$ is $1.8 \%$ in both periods. In this line, the difference between POC and the proportion of deaths due to other causes is also small: $-1.9 \%$ in 1985-1994 and $-1.8 \%$ in 1995-2004. In our study, we associated these improvements with the decrease in the PBC between periods, since we did not find significant differences in the 10-year POC between time periods.

Future research will continue updating the follow-up up to 20 years for the most recent cohort. On the other hand, the data available did not allow us to investigate survival by molecular subtype of breast cancer (e.g., luminal A or B, triple negative, HER2), but evidence suggests that the prognostic value of molecular subtype persists when adjusting for age, stage and histological grade, and certain subtypes may metastasized even when the tumor itself is localized [32]. However, this information will be retrieved for the cohort diagnosed beyond 2000, since hormone's evaluation and HER2 status was not the standard of care in Spain before this year.

\section{Conclusion}

First, our analysis suggests that women diagnosed with BC have higher PBC than POC during the first 10 years after diagnosis. The reduction of $19 \%$ in risk of death beyond 1995 was markedly due to the reduction in the PBC, since the POC did not change between periods. Access to BC screening and the improvements in treatment have had a positive impact on survival prospects of $\mathrm{BC}$ patients. To continue the improvement in long-term survival rates of $\mathrm{BC}$ patients, continued efforts should be pursued in (1) increasing adherence to screening programmes with better quality and in (2) the introduction of therapeutic innovations.
Acknowledgements This work was supported by Instituto de Salud Carlos III through the Project PI14/01041, co-funded by FEDER funds/ European Regional Development Fund (ERDF)-a way to Build Europe-//FONDOS FEDER "una manera de hacer Europa”. The Agència d'Avaluació d'Universitats i Recerca (2014SGR0635) partially supported this study.

\section{Compliance with ethical standards}

Conflict of interest The funders had no role in the design of the study, the collection, analysis, or interpretation of the data, the writing of the manuscript, or the decision to submit the manuscript for publication. The authors state that there are no conflicts of interest concerning this study.

Research involving human participants and/or animals This article does not contain any studies with human participants or animals performed by any of the authors.

Open Access This article is distributed under the terms of the Creative Commons Attribution 4.0 International License (http://creativeco mmons.org/licenses/by/4.0/), which permits unrestricted use, distribution, and reproduction in any medium, provided you give appropriate credit to the original author(s) and the source, provide a link to the Creative Commons license, and indicate if changes were made.

\section{References}

1. Ferlay J, Steliarova-Foucher E, Lortet-Tieulent J, Rosso S, Coebergh JWW, Comber H, et al. Cancer incidence and mortality patterns in Europe: estimates for 40 countries in 2012. Eur J Cancer. 2013;49:1374-403.

2. Galceran J, Ameijide A, Carulla M, Mateos A, Quirós JR, Rojas D, et al. Cancer incidence in Spain, 2015. Clin Transl Oncol. 2017;19(7):799-825.

3. Clèries R, Ameijide A, Marcos-Gragera R, Pareja L, Carulla M, Vilardell ML, Esteban L, Buxó M, Espinàs JA, Puigdefàbregas A, Ribes J, Izquierdo A, Galceran J, Borrás JM. Predicting the cancer burden in Catalonia between 2015 and 2025: the challenge of cancer management in the elderly. Clin Transl Oncol. 2017. https ://doi.org/10.1007/s12094-017-1764-5.

4. Pollán M, Pastor-Barriuso R, Ardanaz E, Argüelles M, Martos $\mathrm{C}$, Galcerán $\mathrm{J}$, et al. Recent changes in breast cancer incidence in Spain, 1980-2004. J Natl Cancer Inst. 2009;101:1584-91.

5. Galceran J, Puigdefàbregas A, Ribas G, Izquierdo A, Pareja L, Marcos-Gragera R. Evolución de la supervivencia del cáncer en Cataluña y comparación con Europa. Med Clin. 2008;131:19-24.

6. Chirlaque MD, Salmerón D, Galceran J, Ameijide A, Mateos A, Torrella A, Jiménez R, Larrañaga N, Marcos-Gragera R, Ardanaz E, Sant M, Minicozzi P, Navarro C, Sánchez MJ; REDECAN Working Group. Cancer survival in adult patients in Spain. Results from nine population-based cancer registries. Clin Transl Oncol. 2018;20(2):201-11.

7. Clèries R, Buxó M, Yasui Y, Marcos-Gragera R, Martínez JM, Ameijide A, et al. Estimating long-term crude probability of death among young breast cancer patients: a Bayesian approach. Tumori. 2016;102:555-61.

8. Croccetti E, Roche L, Buzzoni C, di Costanzo F, Molinié F, Caldarelle A, et al. Trends in net survival from breast cancer in six European Latin countries: results from the SUDCAN populationbased study. Eur J Cancer Prev. 2017;26:S85-91.

9. Clèries R, Martínez JM, Moreno V, Yasui Y, Ribes J, Borràs JM. Predicting the change in breast cancer deaths in Spain by 2019: a Bayesian approach. Epidemiology. 2013;24:454-60. 
10. Allemani C, Minicozzi P, Berrino F, Bastiaannet E, Gavin A, Galceran J, et al. Predictions of survival up to 10 years after diagnosis for European women with breast cancer in 2000-2002. Int J Cancer. 2013;132:2404-12.

11. Chirlaque MD, Salmerón D, Ardanaz E, Galceran J, Martínez R, Marcos-Gragera R, et al. Cancer survival in Spain: estimate for nine major cancers. Ann Oncol. 2010;21(Suppl 3):iii21-9.

12. Brenner H, Hakulinen T. Are patients diagnosed with breast cancer before age 50 years ever cured? J Clin Oncol. 2004;22:432-8.

13. Louwman WJ, Klokman WJ, Coebergh JWW. Excess mortality from breast cancer 20 years after diagnosis when life expectancy is normal. Br J Cancer. 2001;84:700-3.

14. Woods LM, Rachet B, Lambert PC, Coleman MP. "Cure" from breast cancer among two populations of women followed for 23 years after diagnosis 2009. Ann Oncol. 2009;20(8):1331-6.

15. Gamel J, Meyer J, Feuer E, Ba M. The impact of stage and histology on the long-term clinical course of 163,808 patients with breast carcinoma. Cancer. 1996;77:1459-64.

16. Janssen-Heijnen MLG, van Steenbergen LN, Voogd AC, TjanHeijnen VCG, Nijhuis PH, Poortmans PM, et al. Small but significant excess mortality compared with the general population for long-term survivors of breast cancer in the Netherlands. Ann Oncol. 2014;25:64-8.

17. Bouillon K, Haddy N, Delaloge S, Garbay J-R, Garsi J-P, Brindel $\mathrm{P}$, et al. Long-term cardiovascular mortality after radiotherapy for breast cancer. J Am Coll Cardiol. 2011;57:445-52.

18. Dal Maso L, Guzzinati S, Buzzoni C, Capocaccia R, Serraino D, Caldarella A, et al. Long-term survival, prevalence, and cure of cancer: a population-based estimation for 818,902 Italian patients and 26 cancer types. Ann Oncol. 2014;25(11):2251-60.

19. IDESCAT - Institute of Statistics of Catalonia 2015. Stat Year Book of Catalonia 2015:2015. http://www.idescat.cat/en/poblacio/ poblrecomptes.html. Accessed 10 Nov 2017.

20. Fleming ID, Cooper JS, Henson DE, et al., editors. AJCC Cancer Staging Manual. 5th ed. Philadelphia: Lippincott-Raven; 1997.

21. Cronin KA, Feuer EJ. Cumulative cause-specific mortality for cancer patients in the presence of other causes: a crude analogue of relative survival. Stat Med. 2000;19:1729-40.
22. Pohar Perme M, Estève J, Rachet B. Analysing populationbased cancer survival-settling the controversies. BMC Cancer. 2016;16:933.

23. Pohar M, Stare J. Relative survival analysis in R. Comput Methods Programs Biomed. 2006;81:272-8. https://doi.org/10.1016/j. cmpb.2006.01.004.

24. Feinstein A, Sosin D, Wells C. The Will Rogers phenomenon. Stage migration and new diagnostic techniques as a source of misleading statistics for survival in cancer. N Engl J Med. 1985;312:1604-8.

25. Singletary SE, Connolly JL. Breast cancer staging: working with the sixth edition of the AJCC Cancer Staging Manual. CA Cancer J Clin. 2006;56:37-47.

26. Olivotto IA, Chua B, Allan SJ, Speers CH, Chia S, Ragaz J. Longterm survival of patients with supraclavicular metastases at diagnosis of breast cancer. J Clin Oncol. 2003;21(5):851-4.

27. Woods LM, Morris M, Rachet B. No, "cure" within 12 years of diagnosis among breast cancer patients who are diagnosed via mammographic screening: women diagnosed in the West Midlands region of England 1989-2011. Ann Oncol. 2016;27:2025-31.

28. Clèries R, Rooney RM, Vilardell M, Espinàs JA, Dyba T, Borras JM. Assessing predicted age-specific breast cancer mortality rates in 27 European countries by 2020 . Clin Transl Oncol. 2018;20(3):313-21.

29. Kramer BS, Welch HG, Prorok PC, O’Malley AJ, Kramer BS. Breast-Cancer Tumor Size, Overdiagnosis, and Mammography Screening Effectiveness. N Engl J Med. 2016;375:1438-47.

30. Martinez-Alonso M, Vilaprinyo E, Marcos-Gragera R, Rue M. Breast cancer incidence and overdiagnosis in Catalonia (Spain). Breast Cancer Res. 2010;12(4):R58.

31. Duffy SW, Etzioni R, Sasieni P. Both a stage shift and changes in stage-specific survival have contributed to reductions in breast cancer mortality. Evid Based Med. 2017;22:76.

32. Puig-Vives M, Sánchez MJ, Sánchez-Cantalejo J, Torrella-Ramos A, Martos C, Ardanaz E, et al. Distribution and prognosis of molecular breast cancer subtypes defined by immunohistochemical biomarkers in a Spanish population-based study. Gynecol Oncol. 2013;130:609-14.

\section{Affiliations}

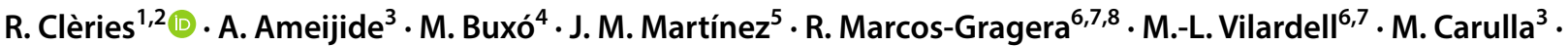 Y. Yasui ${ }^{9} \cdot$ M. Vilardell $^{10} \cdot$ J. A. Espinàs ${ }^{1} \cdot$ J. M. Borràs ${ }^{1,2} \cdot$ J. Galceran $^{3,11} \cdot$ À. Izquierdo $0^{6,7,12}$}

1 Pla Director d'Oncologia (GENCAT), IDIBELL, Hospital Duran i Reynals, Gran Via 199-203 $1^{\text {a }}$ planta, L'Hospitalet de Llobregat, 08908 Barcelona, Spain

2 Departament de Ciències Clíniques, Universitat de Barcelona, Campus de Bellvitge, L’Hospitalet de Llobregat, Barcelona, Spain

3 Registre de Càncer de Tarragona, Fundació Lliga per a la Investigació i Prevenció del Càncer (FUNCA)-IISPV, Reus, Tarragona, Spain

4 Institut d'Investigació Biomèdica de Girona, IDIBGI, C/Dr.Castany s/n, Edifici M2, Parc Hospitalari Martí i Julià, 17190 Salt, Spain

5 MC MUTUAL, Departamento de Investigación y Análisis de Prestaciones, C/Provenza, 321, 08037 Barcelona, Spain

6 Unitat d'Epidemiologia i Registre del Càncer de Girona (UERGG), Institut d'Investigació Biomèdica Girona Josep Trueta (IDIBGI), Girona, Spain
7 Institut Català d'Oncologia (ICO), Girona, Spain

8 Departament d'Infermeria, Universitat de Girona (UdG), Girona, Spain

9 Department of Epidemiology and Cancer Control, St. Jude Children's Research Hospital, Memphis, TN 38105, USA

10 Sección de Estadística del Departamento de Genética, Microbiología y Estadística de la Facultad de Biología, Universidad de Barcelona, 08028 Barcelona, Spain

11 Departament de Medicina i Cirurgia, Universitat Rovira i Virgili, Reus, Tarragona, Spain

12 Departament d'Oncología Médica, Institut Català d'Oncologia, Hospital Universitari Doctor Josep Trueta, Girona, Spain 